Available online at: http://journal.unj.ac.id

Jurnal
Pensil

Journal homepage: http://journal.unj.ac.id/unj/index.php/ipensil/index

\title{
PENGEMBANGAN E-MODUL BERBASIS ANDROID MATA KULIAH STRUKTUR BETON II
}

\section{DEVELOPMENT OF ANDROID-BASED E-MODULES COURSE OF CONCRETE STRUCTURE II}

\author{
Anggita Rachmi \\ Universitas Negeri Jakarta, JL. Rawamangun Muka, Jakarta Timur, 13122, Indonesia \\ rachmi.anggita@gmail.com
}

\begin{abstract}
Abstrak
Penelitian ini merupakan penelitian dan pengembangan yang bertujuan

P-ISSN: $\underline{2301-8437}$

E-ISSN: $\underline{2623-1085}$

ARTICLE HISTORY

Accepted:

2 April 2019

Revision:

19 September 2020

Published:

20 September 2020

ARTICLE DOI:

$\overline{\overline{10.21009 / \text { ipensil.v9i3.10815 }}}$

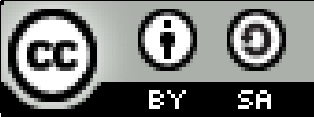

Jurnal Pensil : Pendidikan Teknik Sipil is licensed under a Creative Commons Attribution-SbareAlike 4.0 International License (CC BY-SA 4.0). untuk mengembangkan bahan ajar pembelajaran berupa e-modul berbasis Android pada Struktur Beton II. Metode yang digunakan dalam penelitian ini adalah Research and Development dengan model ADDIE. Model pengembangan ini memiliki 5 tahapan, yaitu menganalisis, merancang, mengembangkan, mengimplementasikan, dan mengevaluasi. Namun, penelitian ini hanya sampai tahap pengembangan. Alat ukur yang digunakan adalah alat ukur kelayakan bahan ajar menurut ahli materi dan ahli media. Penelitian ini dilakukan oleh ahli materi dengan nilai $93,26 \%$ yang dapat dikategorikan "Sangat Layak". Sedangkan, nilai menurut ahli media diperoleh nilai sebesar 97,22\% yang dapat dikategorikan "Sangat Layak".

Kata kunci: E-modul, Android, Struktur Beton

Abstract

This study is a research and development which has the aim to develop learning instructional materials in the form of Android-based e-modules in Concrete Structure II. The method used in this research is Research and Development with ADDIE model. This development model has 5 stages, namely analyzing, designing, developing, implementing, and evaluating. However, this research only applies to the development stage. The measuring instrument used is an instrument to measure the feasibility of teaching materials by material experts and media expert. This research was carried out by material experts value was 93,26\% which could be categorized as "Very Decent". While the value by media experts obtained a value of $97,22 \%$ which can be categorized as "Very Decent".
\end{abstract}

Keywords: E-module, Android, Concrete Structure 


\section{Pendahuluan}

Perkembangan teknologi modern saat ini menjadikan manusia lebih praktis dan efisien untuk mendapatkan informasi terbaru. Pada tahun 2018, penggunaan teknologi aktif smartphone sendiri mencapai 100 juta orang di Indonesia (Kementrian Perindustrian, 2018). Pengguna smartphone didominasi berusia 18-29 tahun yang umumnya berprofesi pelajar perkuliahan, namun penelitian menyatakan smartphone dapat digunakan sebagai alat pembelajaran yang efektif dan efisien (Crompton \& Burke, 2018, p. 1-10).

Perkembangan teknologi smartphone saat ini memberikan dampak yang sangat besar bagi manusia, salah satunya di dunia pendidikan. Dampak negatif yang diterima oleh peserta didik yaitu menjadi enggan belajar dan dominan bermain smartphone. Namun, kualitas smartphone yang hampir menyerupai komputer atau laptop dapat dimanfaatkan oleh pendidik sebagai penunjang berjalannya kegiatan proses belajar mengajar. Mobile learning memungkinkan peserta didik dapat memperoleh pembelajaran berupa materi, arahan dan informasi pembelajaran dimana pun dan kapan pun tidak terbatas ruang dan waktu (Rio, dkk., 2017, p. 64).

Salah satu perangkat yang perlu dipersiapkan dalam proses belajar mengajar adalah bahan ajar. Bahan ajar merupakan suatu materi atau isi pelatihan yang diwujudkan dalam bentuk benda sehingga dapat digunakan dalam proses pembelajaran (Hernawan, dkk., 2012, p. 3).

Salah satu bahan ajar yang dapat digunakan mahasiswa secara mandiri yaitu modul. Sehubungan dengan teknologi yang semakin canggih, umumnya modul disajikan dalam wujud cetakan maka dengan menggunakan teknologi elekronik, modul yang dapat disajikan dalam bentuk digital disebut e-modul (Vembrianto dalam Handhika, dkk., 2017, p. 118). Alat pembelajaran yang dapat digunakan untuk menyalurkan e-modul dapat berupa smartphone. Penelitian dan pengembeangan mengenai e-modul berbasis Android memiliki penelitian relevan yang menyatakan modul pembelajaran berbasis Android mobile efektif untuk kemampuan peserta didik (Aminatun, dkk., 2016, p. 228).

Capaian pembelajaran S1 Pendidikan Teknik Bangunan (PTB) UNJ dikhususkan pada bidang teknik struktur dan teknik menggambar (FT UNJ, 2018). Terdapat 5 kelompok mata kuliah yang diampu di S1 PTB UNJ dan didominasi oleh kelompok mata kuliah bidang penunjang. Mata kuliah bidang penunjang yang membahas mengenai teknik struktur pembetonan adalah Struktur Beton II. Persentase nilai A mata kuliah Struktur Beton II oleh mahasiswa tahun ajaran 2013/2014 sebesar $17,5 \%$ dan tahun ajaran 2015/2016 sebesar 8,625 , sehingga dapat disimpulkan mahasiswa yang mendapatkan nilai A pada mata kuliah Struktur Beton II memiliki penurunan.

Model pembelajaran yang diterapkan pada matakuliah Struktur Beton II di S1 PTB UNJ menggunakan model Problem Based Learning (PBL). Dalam mencapai tujuan pembelajaran dan membantu peserta didik menyelesaikan mata kuliah Struktur Beton II, maka dilakukan pengembangan bahan ajar e-modul berbasis Android. Adanya pengembangan e-modul berbasis Android diharapkan dapat membantu peserta didik dalam menuntaskan mata kuliah Struktur Beton II.

Hasil survey pengembangan e-modul berbasis Android kepada beberapa mahasiswa S1 PTB UNJ menunjukkan persentase sebesar $80 \%$ menyatakan sangat memerlukan bahan ajar mata kuliah Struktur Beton II dalam bentuk elektronik. Hal ini dikarenakan dalam proses pembelajaran pada mata kuliah Struktur Beton II di Pendidikan Teknik Bangunan UNJ menerapkan model pembelajaran Problem Based Learning (PBL), sehingga 
referensi bahan ajar yang digunakan kurang.

Berkaitan uraian di atas, maka dilakukan penelitian pengembangan emodul berbasis Android pada mata kuliah Struktur Beton II di PTB UNJ. Pengembangan ini diharapkan dapat membantu dosen dan mahasiswa dalam menyampaikan materi perkuliahan sehingga dapat memberikan ide dan perkembangan dalam dunia pembelajaran bagi lembaga, meningkatkan hasil belajar mahasiswa pada mata kuliah tersebut, serta menambah dan mendalami pengetahuan dan wawasan mengenai Struktur Beton II di Pendidikan Teknik Bangunan Universeitas Negeri Jakarta.

$$
\text { Agar pokok bahasan tidak }
$$
menyimpang dari topik utama, maka lingkup pembahasan dalam penyusunan skripsi ini antara lain penelitian dilakukan di Program Studi S1 PTB Fakultas Teknik UNJ, materi modul berdasarkan Rancangan Pembelajaran Semester (RPS) Struktur Beton II, bahan ajar mencakup materi sesuai RPS, pedoman untuk mengerjakan tugas besar, contoh soal, dan soal untuk evaluasi yang disertai kunci jawaban, e-modul yang digunakan berbasis Android tanpa menggunakan jaringan atau offline, dan uji validasi oleh ahli materi (berdasarkan RPS) dan percobaan kebutuhan. Berdasarkan identifikasi masalah dan pembatasan masalah, maka masalah dapat dirumuskan sebagai berikut: Bagaimana relevansi materi ajar Mata Kuliah Prodi di Prodi PTB FT UNJ dengan materi ajar di SMK Negeri bidang keahlian Teknik Bangunan di Jakarta.

\section{Metode Penelitian}

Perancangan penggunaan e-modul berbasis Android pada mata kuliah Struktur Beton II yaitu berdasarkan model pengembangan ADDIE yang telah dikembangkan oleh Robert Maribe. Namun, penelitian ini hanya menerapkan dari proses analisis sampai proses pengembangan.

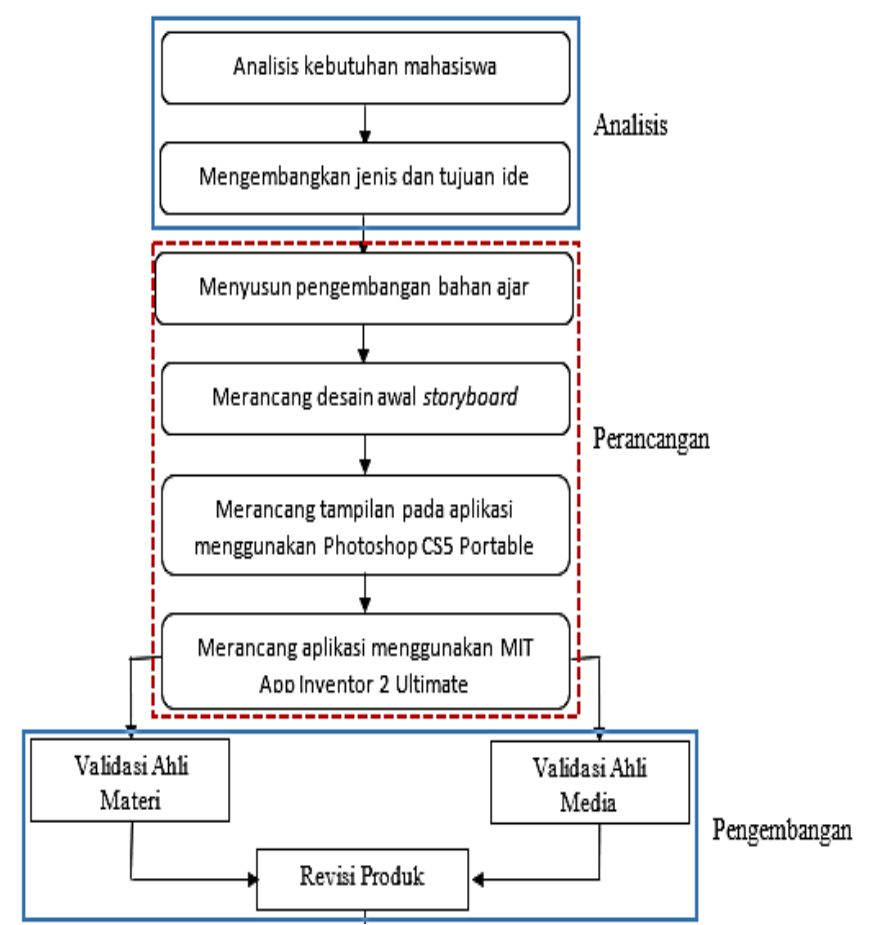

Gambar 1. Alur Perencanaan E-Modul Berbasis Android Menggunakan Model ADDIE

Penelitian dan pengembangan merupakan mengembangkan media pembelajaran yang belum ada atau menyempurnakan media pembelajaran yang sudah ada. Hasil perancangan produk awal akan divalidasi oleh ahli dari beberapa bidang menggunakan sebuat alat ukur, yaitu instrumen non tes. Alat ukur yang digunakan dalam memperoleh hasil dari suatu kegiatan/program dapat bersifat kuantitatif/angka (Arthur, 2013, p. 6). Data kualitatif yang diperoleh berupa masukan, tanggapan, dan saran (Riyadi, dkk., 2017, p. 34) dari validasi ahli.

\section{Hasil Penelitian dan Pembahasan}

Produk yang ditampilan membahas mengenai Rancangan Pembelajaran Semester (RPS) mata kuliah Struktur Beton II, materi mata kuliah Struktur Beton II, evaluasi pembelajaran dan tentang 
mengenai aplikasi e-modul Struktur Beton II. Materi disajikan dalam bentuk modul yang ditampilkan dalam aplikasi. Materi dan evaluasi Struktur Beton II disesuaikan dengan tujuan pencapaian mata kuliah yang tercantum di dalam RPS. Modul disesuaikan dengan RPS mata kuliah Struktur Beton II, maka terdapat 4 modul yaitu modul struktur pelat, modul balok, modul kolom, dan modul podnasi telapak. Sehingga pemilihan referensi pembuatan modul disesuaikan dengan RPS agar tidak menyimpang dari tujuan pembelajaran.

Penyusunan materi e-modul berbasis Android disesuaikan dengan kerangka modul. Maka e-modul memiliki kerangka atau penyusunan yang sama dengan modul, namun e-modul disajikan dalam bentuk digital sedangkan modul umumnya berbentuk cetak.

Tampilan produk dirancang dengan bantuan aplikasi Adobe Photoshop CS5 Portable. Tampilan aplikasi disesuaikan dengan pengguna aplikasi, yaitu mahasiswa yang sedang mengambil mata kuliah Struktur Beton II (Semester 4). Pembuatan produk aplikasi menggunakan MIT App Inventor 2 Ultimate.

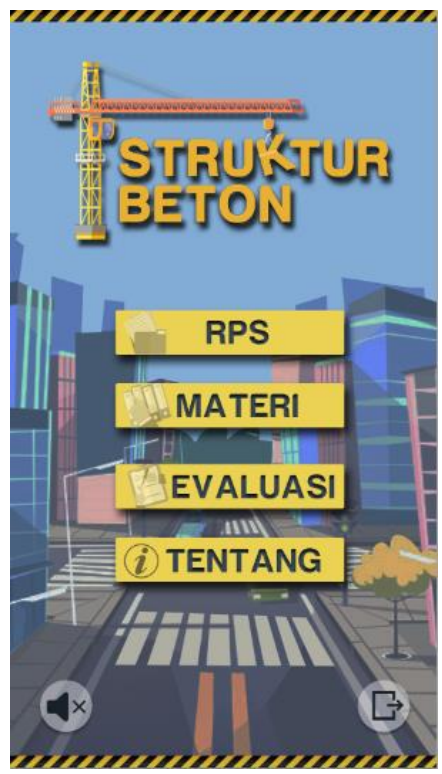

Gambar 2. Tampilan Utama E-Modul Berbasis Android Struktur Beton II

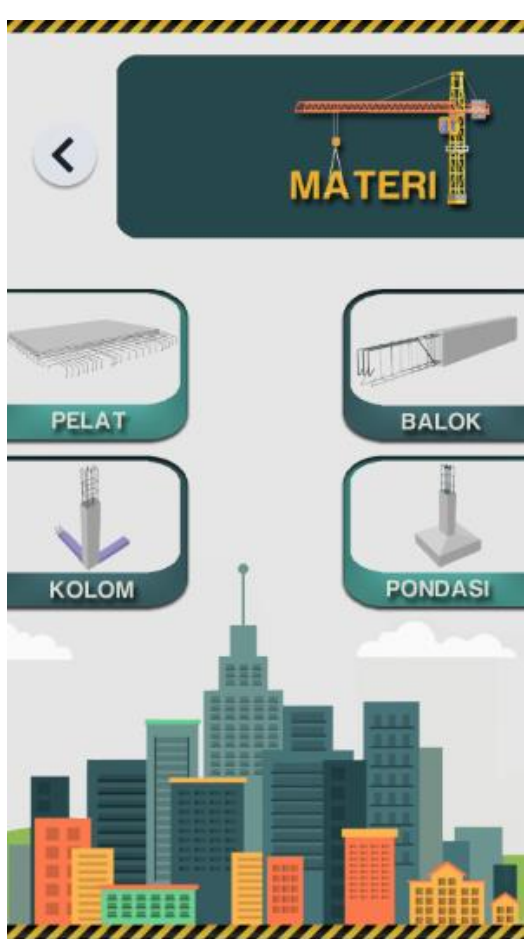

Gambar 3. Tampilan Menu Materi Struktur Beton II

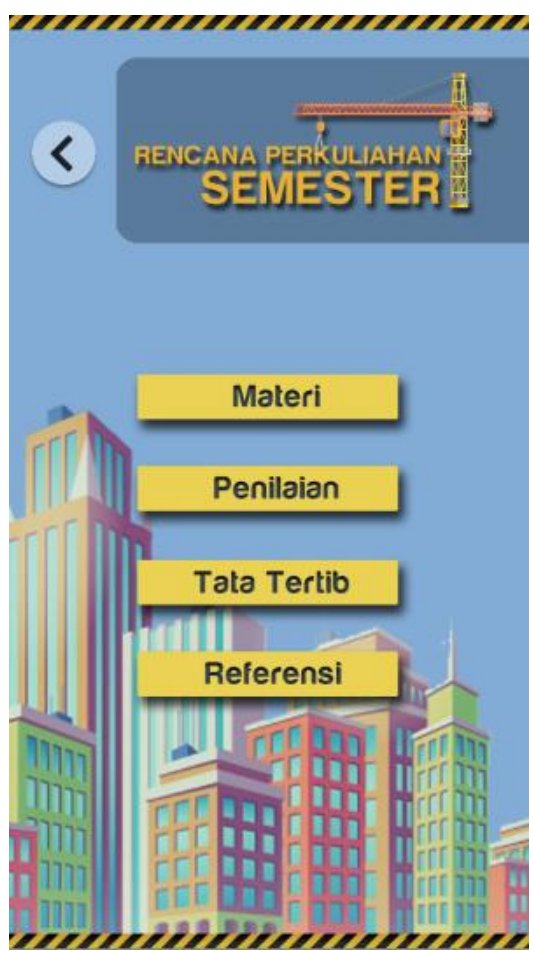

Gambar 4. Tampilan Menu RPS EModul Berbasis Android Struktur Beton II 


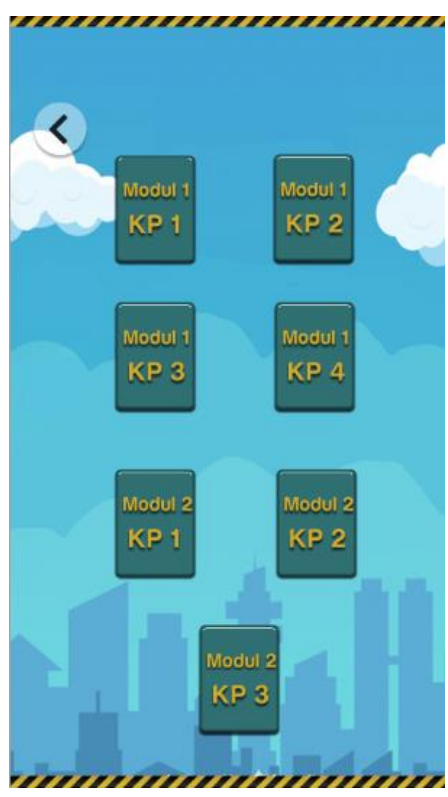

Gambar 5. Tampilan Menu Tes Formatif Struktur Beton II

Validasi penelitian ini dilakukan oleh 5 ahli, yaitu terdiri dari 3 ahli media dan 2 ahli materi. Ahli media pembelajaran terdiri dari dua orang dosen dari Program Studi Teknologi Pendidikan UNJ dan satu orang instansi Pustekkom Kemdikbud. Sedangkan ahli materi terdiri dari dua dosen struktur beton di Program Studi Pendidikan Teknik Bangunan UNJ. Adapun hasil penilaian dari ahli media sebagai berikut.

Tabel 1. Data Hasil Validasi Ahli Media

\begin{tabular}{clcc}
\hline $\begin{array}{c}\text { No } \\
\cdot\end{array}$ & \multicolumn{1}{c}{$\begin{array}{c}\text { Aspek } \\
\text { Validasi }\end{array}$} & $\begin{array}{c}\text { Total } \\
\text { Persentase }\end{array}$ & Kategori \\
\hline 1 & Bahasa & $100 \%$ & $\begin{array}{c}\text { Sangat } \\
\text { Baik }\end{array}$ \\
\hline 2 & $\begin{array}{l}\text { Pemilihan } \\
\text { Warna }\end{array}$ & $100 \%$ & $\begin{array}{c}\text { Sangat } \\
\text { Baik }\end{array}$ \\
\hline 3 & $\begin{array}{l}\text { Pemilihan } \\
\text { Huruf }\end{array}$ & $100 \%$ & $\begin{array}{c}\text { Sangat } \\
\text { Baik }\end{array}$ \\
\hline 4 & Suara & $83,33 \%$ & Baik \\
\hline 5 & $\begin{array}{l}\text { Pengoperasian } \\
\text { Media }\end{array}$ & $100 \%$ & $\begin{array}{c}\text { Sangat } \\
\text { Baik }\end{array}$ \\
\hline 6 & $\begin{array}{l}\text { Kreativitas } \\
\text { Pengembangan }\end{array}$ & $100 \%$ & $\begin{array}{c}\text { Sangat } \\
\text { Baik }\end{array}$ \\
\hline & Jumlah & $\mathbf{9 7 , 2 2 \%}$ & $\begin{array}{c}\text { Sangat } \\
\text { Baik }\end{array}$ \\
\hline
\end{tabular}

Penilaian media e-modul Struktur Beton II berdasarkan aspek-aspek validasi, antara lain kemudahan bahasa yang digunakan pada tombol navigasi, kombinasi warna, kejelasan huruf pada emodul, suara yang bersih, kelancaran penggunaan aplikasi e-modul, dan kreativitas pengembangan. Jumlah penilaian ahli media terhadap e-modul berbasis Android sebesar 97,22\% yang dapat disimpulkan bahwa aplikasi e-modul berbasis Android dapat dikategorikan sangat baik dan layak digunakan sebagai bahan ajar pada mata kuliah Struktur Beton II.

Saran yang diberikan oleh ahli media yaitu melengkapi RPS yang terdapat di dalam e-modul berbasis Android, scroll aplikasi yang digunakan tidak seragam, nomor halaman dihilangkan, digunakan huruf sanserif, tombol navigasi soal diubah menjadi evaluasi yang disesuaikan dengan Kegiatan Pembelajran, perlu diberikan petunjuk untuk penggunaan bagian yang sulit serta backsound perlu diubah. Adapun hasil penilaian oleh ahli materi dapat diuraikan sebagai berikut.

Tabel 2. Data Hasil Validasi Ahli Materi

\begin{tabular}{ccc}
\hline Modul & $\begin{array}{c}\text { Total } \\
\text { Persentase }\end{array}$ & Kategori \\
\hline $\mathbf{1}$ & $93,33 \%$ & Sangat Baik \\
\hline $\mathbf{2}$ & $91,11 \%$ & Sangat Baik \\
\hline $\mathbf{3}$ & $94,17 \%$ & Sangat Baik \\
\hline $\mathbf{4}$ & $94,44 \%$ & Sangat Baik \\
\hline $\begin{array}{c}\text { Jumlah } \\
\text { Persentase }\end{array}$ & $\mathbf{9 3 , 2 6 \%}$ & Sangat Baik \\
\hline
\end{tabular}

Penilaian masing-masing materi modul Struktur Beton II berdasarkan aspek-aspek validasi, antara lain mencakup materi yang disajikan sesuai dengan RPS, tahapan penjelasan materi berawal dari umum menjadi lebih kompleks, evaluasi sesuai dengan materi modul, dan strategi pembelajaran sehingga bahan ajar dapat memudahkan mahasiswa belajar. Jumlah penilaian ahli media terhadap e-modul 
berbasis Android sebesar 97,22\% yang dapat disimpulkan bahwa aplikasi e-modul berbasis Android dapat dikategorikan sangat baik dan layak digunakan sebagai bahan ajar pada mata kuliah Struktur Beton II.

Saran yang diberikan oleh ahli materi yaitu bahasa ilmiah yang perlu disesuaikan, perlu penguatan materi sehingga tidak umum, mencantumkan sumber materi, keterangan materi dan contoh soal perlu dilengkapi, memperjelas tujuan materi, serta melengkapi gambar atau video.

Adapun kelebihan dari aplikasi emodul berbasis Android yaitu dapat meningkatkan ketertarikan mahasiswa dalam mempelajari Struktur Beton II secara mandiri, dapat digunakan dimana saja dan kapan saja tidak terbatas oleh ruang dan waktu, serta dapat memudahkan peserta didik dalam proses belajar.

Namun, aplikasi e-modul berbasis Android memiliki kekurangan antara lain tahapan penelitian hanya sampai pada tahap proses pengembangan maka penelitian dapat dilanjutkan pada tahap penerapan yaitu uji coba kepada mahasiswa, dalam menentukan warna yang akan digunakan dalam aplikasi harus disesuaikan dengan karakteristik dan selesara mahasiswa agar dapat menimbulkan rasa ketertarikan dalam mempelajari materi pembelajaran, merancang aplikasi Android membutuhkan waktu yang lebih karena harus mempelajari pembuatan aplikasi terlebih dahulu, mahasiswa diharuskan memiliki teknologi seperti smartphone atau laptop untuk dapat mempelajari bahan ajar Struktur Beton II.

E-modul berbasis Android digunakan saat mahasiswa berada di rumah secara mandiri sehingga mahasiswa dapat mempelajari materi pembelajaran yang akan datang terlebih dahulu. Pada proses pembelajaran di kelas, mahasiswa akan berdiskusi dengan teman kelompok mengenai materi e-modul berbasis Android. Mata kuliah Struktur Beton II menggunakan model pembelajaran PBL, sehingga e-modul berbasis Android dapat digunakan sebagai pedoman atau referensi mahasiswa dalam mengerjakan tugas besar.

\section{Simpulan}

Pengembangan e-modul berbasis Android ini mengikuti tahapan ADDIE yaitu diawali dengan menganalisis kebutuhan mahasiswa, mencari referensi materi Struktur Beton II, merancang modul, mendesain tampilan produk, membuat storyboard produk, merancang produk, dan melakukan validasi kepada ahli media dan ahli materi, dan melakukan revisi produk dari penilaian para ahli. Hasil keseluruhan penilaian validasi ahli materi dan ahli media memperoleh nilai sebesar $95,24 \%$ yang dapat digolongkan sangat baik dan layak digunakan. Sehingga dapat ditarik kesimpulan bahwa e-modul berbasis Android telah layak digunakan sebagai bahan ajar pada mata kuliah Struktur Beton II.

Berdasarkan hasil dari penelitian dan pengembangan e-modul berbasis Android ini, maka penulis memberikan saran sebagai berikut: 1) Produk pengembangan e-modul berbasis Android dapat digunakan secara online sehingga mahasiswa dapat berdiskusi mengenai materi perkuliahan Struktur Beton II; dan 2) Produk dapat dikembangkan menuju tahapan pengembangan selanjutnya yaitu proses penerapan dan evaluasi. Proses penerapan dilakukan dengan cara melakukan uji coba kepada mahasiswa-mahasiswa yang telah menggunakan produk, sehingga dapat dievaluasi pengaruh hasil belajar dari penggunaan e-modul berbasis Android terhadap mahasiswa

\section{Daftar Pustaka}

Aminatun, T., et al. (2016). Pengembangan E-Module Berbasis Android Mobile Materi Ekosistem Lokal Nusa Tenggara untuk Meningkatkan 
Keterampilan Berpikir Siswa SMA. SNPS 2016, 2016-2223.

Arthur, R. (2013). Pengukuran Acuan Patokan -Terpadu (PAP-T) dalam Mengukur Kompetensi dalam bidang Teknik Sipil. Seminar Nasional Evaluasi Pendidikan. 1-14.

Crompton, H., \& Burke, D. (2018). Computers \& Education The use of mobile learning in higher education: A systematic review. Computers \& Education, 123: 53-64.

Fakultas Teknik Universitas Negeri Jakarta (2018). Program Studi S1 Pendidikan Teknik Bangunan. Jakarta: Universitas Negeri Jakarta.

Handhika, J., Prastyaningrum, I., \& Pratama, R. (2017). Pengembangan Media Pembelajaran E-Modul
Berbasis Smartphone Pada Materi Hukum Biot Savart, Seminar Nasional Pendidikan Fisika, 117-121.

Hernawan, A. H., Permasih, \& Demi, L. (2012). Pengembangan Bahan Ajar. Jurnal Pendidikan, 1-13.

Rio, P., Feriansyah, S., \& Chandra, E. (2017). Pengembangan Media Pembelajaran Mobile Learning Berbasis Android Sebagai Suplemen Pembelajaran Fisika SMA Pada Materi Usaha dan Energi.

Riyadi, S., Qamar, K., Malang, U. K., \& Timur, J. (2017). Efektivitas EModul Analisis Real Pada Program Studi Pendidikan Matematika, 1(1): 31-40. 